\title{
Local Environmental Legislation in China: Achievements and Challenges
}

\author{
Yue Zhu \\ Graduate School, Chinese Academy Of Social Sciences, Beijing, China. \\ aeonis@qq.com
}

\begin{abstract}
The total number of local environmental legislations is 2908 , which accounts for a considerable proportion of China's local legislation system. Understanding and analyzing local environmental legislation is of great significance for building a system of Chinese environmental law. At present, local environmental legislation has serious problems and cannot meet the needs of local environmental protection. It is recommended to take various measures to improve the quality of local environmental legislation.
\end{abstract}

Keywords: China, environmental law, local legsilation, environmental protection.

\section{Introduction}

Local environmental legislation is an important part of China's ecological civilization system. Due to the different environmental conditions and resource endowments, environmental legislation at the national level generally adopts the principle of general legislation, in which its landing relies on the supplement and refinement of local legislation. Strengthening local environmental legislation is of great significance for implementing national environmental laws and regulations, solving local environmental resources and enhancing the targeted effectiveness of environmental legislation. At present, local environmental legislation in China still has problems such as low quality of legislation, serious delay in the construction of legislative capacity, prominent departmental interests and local protectionism, and imperfect legislative procedures.

\section{A Brief Introduction to China's Local Environmental Legislations}

According to the Law and Regulations Database of the China National People's Congress, as of April 1, 2018, National People's Congress and its Standing Committee has promulgated 28 environmental laws, and the State Council has promulgated 47 environmental protection administrative regulations, the relevant departments of the State Council have promulgated hundreds of environmental administrative rules. Local people's congresses and governments with legislative power have promulgated 2,908 environmental local regulations, local government rules, autonomous decrees and special decrees. Among them, 1,945 are executive legislations promulgated in accordance with the above-mentioned laws and administrative regulations, and 963 are initiative legislations promulgated by localities according to their own actual conditions. Those cover water, atmosphere, noise, soil, solid waste, nuclear pollution prevention, forests, vegetation, grassland, wetlands, rural environment and nature reserves, which provides a legal basis for local environmental protection and resource construction, and plays an important role in promoting local ecological civilization construction. Table 1 below shows the number of Local environmental legislations which is distributed by province.

\section{Main Problems in China's Local Environmental Legislation}

Although local environmental legislation has achieved certain results, however, some local governments place too much emphasis on GDP and economic benefits while ignoring ecological benefits and sustainable development, and pay too much attention to environmental pollution prevention and neglect natural resource protection. Local environmental legislation still cannot meet 
environmental protection needs. Specifically, local environmental legislation mainly has the following problems.

\subsection{Promulgation and Revision not Timely}

Since the 18th National Party Congress, the nation strengthens environmental legislation, enacts strict environmental protection standards and legal liability systems. The old and new coordination of local environmental legislations become a prominent problem. Taking Hebei Province as an example, after the revision of Environmental Protection Law, Prevention and Control of Atmospheric Pollution Law, and Water Pollution Prevention and Control Law, Hebei Province only partially followed up on the Prevention and Control of Atmospheric Pollution Law, and its environmental legislation and water pollution prevention and control legislation were not revised in time. Zhejiang Province, however, there are also some problems in which environmental legislation has not been revised for many years and is lagging behind national environmental legislation. [1] For example, the Prevention and Control of Pollution From Environmental Noise Law was promulgated in 1997, and the "Regulations for the Administration of Ningbo Urban Environmental Noise Compliance Zone" issued by Ningbo City in 1995 has not been revised.

\subsection{Intercepting the Prohibition of the Upper Law and Relaxing the Restrictions}

For example, Water Pollution Prevention and Control Law stipulates that it is forbidden to set up pollutant discharge construction projects in the secondary protection zone of drinking water sources. "Regulations on Ecological Environment Protection of Songtao Reservoir in Hainan Province" and "Regulations on Ecological Environmental Protection of Hainan Province Nandu River" stipulate that existing projects need not be "demolition or closure" as long as they meet the sewage discharge standards. Another example is Article 10 of "Regulations on the Management of the Qilian Mountain National Nature Reserve in Gansu Province", which reduces the scope of prohibited activities specified in Article 26 of "Regulations on Nature Reserves" from 10 items to 3: hunting, abandonment, and burning. [] However, 7 types of behaviors, such as logging, fishing, drug collection, mining, quarrying and dredging, which have been banned by the upper-level law and have occurred frequently in recent years and have significant damage to the ecological environment, have been deliberately ignored.

\subsection{Violation of the Upper Law with Relaxation of Licensing Conditions}

For example, Articles 44 and 45 of Environmental Protection Law stipulate that the state implements a total pollutant discharge control system; if it does not obtain a pollutant discharge permit, it shall not discharge pollutants. Article 19 of "Regulations on Environmental Protection in Hubei Province" stipulates that the total amount of pollutant discharges shall be controlled in areas where industrial concentration, large amount of pollutant discharge, river basins and environmental quality requirements are high. The environmental protection department shall issue a sewage discharge permit for the discharge control indicators that do not exceed the prescribed discharge; if the control index is exceeded, a temporary sewage discharge permit shall be issued. By comparison, the regulations have narrowed the geographical scope of the implementation of the total amount of key pollutants discharged by the upper-level law, and limited it to industrial concentration, areas with large discharges, watersheds, and areas with high environmental quality requirements; and "issuing temporary discharge permits for companies that exceed control targets", which is inconsistent with the provisions of Article 45 of the Environmental Protection Law, "No pollutants can be discharged without obtaining a discharge permit."

\subsection{Violation of the Upper Law with Problems Such as Lowering Standards and Lax Control}

For example, Article 43 of Environmental Protection Law stipulates that enterprises and institutions that discharge pollutants and other production and business operators shall pay sewage charges in accordance with relevant state regulations. Article 17 of "Regulations on Environmental Protection in Hubei Province" stipulates that all units and individual industrial and commercial 
households discharge sewage and sulfur dioxide into the environment, and pay sewage charges according to regulations. If the pollutants discharged exceed the national or provincial standards for pollutant discharge, they must pay the excessive sewage charges according to the regulations. Comparing the two clauses, "Regulations on Environmental Protection in Hubei Province" narrowed the scope of the payment of sewage charges to the units and individual industrial and commercial households that "discharged sewage and sulfur dioxide to the environment" and did not stipulate environmental protection tax.

\subsection{A Lot of Blanks in Local Environmental Legislation}

In some provinces of China, there are a large number of legislative gaps in the rural environment and nature reserves. There are 51 environmental legislations in Hubei Province, and only one provincial and municipal environmental legislation. The production of Cordyceps in Qinghai Province accounts for about 33\% of the national production of Cordyceps [3], but the relevant environmental legislation in Qinghai Province does not mention the prohibition of excessive use of Cordyceps.

\subsection{Lack of Local Characteristics and Targeted Operability}

In some places, the environmental legislation is not close enough to the local reality. They are copied from relevant legsilation of other provinces, lacking local characteristics and targeted operation. For example, Liaoning Province is rich in mineral resources and is China's heavy industry base. Over the years, the unreasonable economic development of the old industrial base has deteriorated the ecological environment. However, there are not many legislations in Liaoning Province to strengthen the regulation of natural resources such as land, minerals and energy, and to avoid waste of resources and irrational development. There are also fewer legislative initiatives.

\section{Suggestions for Strengthening and Improving Local Environmental Legislation}

In order to improve the local environmental legislation and the legal system of ecological civilization, the following suggestions are proposed.

\subsection{Comprehensively Cleaning up Local Environmental Legislation}

It is recommended that local governments establish a local environmental legislation clean-up leading group, which is led by the provincial people's congress standing committee, the government legal office and the environmental protection administrative department, conducts a comprehensive self-examination of environmental legislation in the region, and proposes to reform and abolish. The results of the clean-up and related recommendations shall be reported to the Law Commission of the Standing Committee of the National People's Congress. Considering that some localities have also formulated a large number of normative documents related to environmental protection, and some have violated the environmental protection law, it is recommended that the local environmental protection normative documents shall be included in the scope of the clean-up above. After the cleanup, the joint supervision mechanism of the Standing Committee of the National People's Congress, the Legislative Affairs Office of the State Council and the Ministry of Ecology and Environment shall be established. For all localities that do not promptly formulate and amend environmental legislation in the region in accordance with the superior law, urge the provincial people's congress standing committee to promptly introduce supporting legislation. Proposal for revision and improvement of the prohibition of the prohibition of the upper-level law, the relaxation of the restrictive provisions of the national-level law, the relaxation of administrative licenses and administrative penalties, and the reduction of standard management and control. For the existence of legislative gaps, urge the legislature to enrich and improve as soon as possible. For the lack of local characteristics and targeted operational deficiencies, the NPC Standing Committee should strengthen the work guidance for local legislatures, strengthen personnel training, and improve the legislative level. All localities should 
include relevant legislative items in their 2018 legislative work plans or the next five-year legislative plan, clarify the responsible units and time limits for completion, and ensure that relevant legislative tasks are completed on time and in good quality.

\subsection{Strengthenning the Review of Laws and Regulations}

According to the provisions of the legislative regulations, regulations and regulations, the Standing Committee of the National People's Congress and the Legislative Affairs Office of the State Council shall file local decrees and local government rules. Due to the heavy task, the clues and the small number of personnel in the filing organs, the local legislation for reporting has to adopt the method of spot checks and key examinations, resulting in some local environmental legislation "taking sickness to work". It is recommended to strengthen the NPC Standing Committee and the State Council Legislative Affairs Office for the filing of work, enrich personnel, strengthen work training, and improve the level of filing. For local environmental legislation, it is necessary to review it one by one, and solicit opinions from relevant departments such as environmental protection. When the relevant local people's congresses and the government report and file for filing, all the laws and regulations of the local people's laws and regulations have been deleted, increased, or modified in terms of the prohibitive provisions and restrictive provisions of the upper-level law, and are inconsistent with the provisions of the superior laws in terms of licensing, punishment, and compulsory, all need to be explained.

\subsection{Increasing the Intensity of Information Disclosure}

Public participation is an important guarantee for the scientific and democratic environmental legislation. The newly revised Environmental Protection Law has added Chapter V "information disclosure and public participation". It is necessary to further improve the public participation system in the local environmental legislation, such as project establishment, implementation, and postevaluation, to ensure the public participation in the authenticity, extensiveness, and representativeness of environmental legislation, and to continuously improve the quality and level of local environmental legislation. At the same time, local environmental legislation should further expand the scope of active disclosure of government environmental information, standardize and smooth channels for application disclosure. Moreover, Local environmental legislation should strengthen the responsibility of corporate environmental information disclosure, and ensure the public's right to know, participate, supervise and seek legal remedies.

\subsection{Conducting Post-legislative Assessments of Local Environmental Legislation}

In recent years, the Chinese central government has proposed a series of new regulations on new environmental protection policies, as well as some basic and comprehensive environmental legislation that have been issued for a long time and are not suitable for actual needs. It is recommended that the Standing Committee of the National People's Congress and the local legislature select a number of basic and comprehensive environmental legislations that are widely concerned by the masses, conduct a comprehensive assessment of the effectiveness of their formulation and implementation, and promote relevant legislation in a timely manner.

\section{Conclusion}

This paper counted China's local environmental legislations and compares local environmental legislations with national environmental laws. On this basis, the legislative blanks and legislative lags of local environmental legislation are analyzed. It is necessary to comprehensively clean up local environmental legislation, strengthen the level of filling, increase the intensity of information disclosure and conduct post-legislative evaluation of key environmental legislation. 


\section{References}

[1]. Swanson K Kuhn R GU W. Environmental policy implementation in rural China: a case study of Yichang, Zhejiang. Environmental Management, Vol. 27 (2001) No.4.

[2]. Information on http://www.chinadaily.com.cn/china/2017-07/21/content_30213753.htm.

[3]. Information on http://www.chongcaowang.net/jianbie/jianbie204.html. 